\title{
Eficácia de herbicidas Aplicados nas Épocas Seca e Úmida PaRa O CONTROLE DE Euphorbia heterophylla NA CULTURA DA CANA-DE-AÇÚCAR
}

\author{
Efficacy of Herbicides Applied During the Dry and Wet Seasons for Euphorbia heterophylla \\ Control in Sugarcane
}

CORREIA, N.M. ${ }^{2}$ e KRONKA JR., B. ${ }^{3}$

\begin{abstract}
RESUMO - Objetivou-se estudar o efeito de herbicidas aplicados em pré e pós-emergência, isolados e em combinações nas épocas seca e úmida, para o controle de leiteiro (Euphorbia heterophylla) na cultura de cana-de-açúcar. O experimento foi desenvolvido no período de agosto de 2008 a junho de 2009, em área de produção comercial de cana-de-açúcar localizada no município de Jaboticabal-SP. O delineamento experimental foi o de blocos ao acaso, com quatro repetições, em esquema de parcela subdividida. $\mathrm{Na}$ época seca foram avaliados os herbicidas amicarbazone (1.400 $\left.\mathrm{g} \mathrm{ha}^{-1}\right)$, imazapic $\left(147 \mathrm{~g} \mathrm{ha}^{-1}\right)$ e sulfentrazone $\left(900 \mathrm{~g} \mathrm{ha}^{-1}\right)$, aplicados em 1/8/2008 após a colheita da cana, e testemunha sem manejo prévio das plantas daninhas. Os herbicidas utilizados na época úmida foram: mesotrione isolado (192 $\left.\mathrm{g} \mathrm{ha}^{-1}\right) \mathrm{e}$ em mistura (120 $\left.\mathrm{g} \mathrm{ha}^{-1}\right)$ com ametryn $\left(1.500 \mathrm{~g} \mathrm{ha}^{-1}\right)$, atrazine $\left(1.500 \mathrm{~g} \mathrm{ha}^{-1}\right)$ ou diuron + hexazinone $\left(702\right.$ + $\left.198 \mathrm{~g} \mathrm{ha}^{-1}\right)$, aplicados em 14/11/2008, além de testemunha capinada e outra sem manejo das plantas daninhas. A aplicação de imazapic na época seca foi eficaz no controle de $E$. heterophylla, dispensando a complementação de manejo na época úmida. No entanto, para os herbicidas amicarbazone e sulfentrazone houve necessidade da aplicação de mesotrione, isolado ou em mistura com ametryn, atrazine ou diuron + hexazinone, para a manutenção do controle de $E$. heterophylla na época úmida (de 105 a 230 dias após a aplicação na época seca). Quando não foi realizada a aplicação de herbicida na época seca, constatou-se melhor controle de E. heterophylla na época úmida com o herbicida mesotrione associado a ametryn, atrazine ou diuron + hexazinone do que quando aplicado isoladamente. Apesar dos sintomas visuais de fitointoxicação ocasionados pelos tratamentos mesotrione + ametryn e mesotrione + (diuron + hexazinone) pulverizados na época úmida, nenhum dos manejos adotados ou combinações entre eles interferiu no número de colmos viáveis por metro linear, no diâmetro e na altura de colmos de cana-de-açúcar.
\end{abstract}

Palavras-chave: combinação de herbicida, leiteiro, planta daninha, palha, Saccharum officinarum.

\begin{abstract}
An experiment was carried out in a commercial sugarcane plantation area in Jaboticabal, Sao Paulo, Brazil, from August 2008 to June 2009 to evaluate the effect of herbicides applied in preemergence and postemergence, alone and combination, during the dry and wet seasons, for poinsettia control (Euphorbia heterophylla). The experiment was arranged in a randomized block design in split-plot, and four replications. Three herbicide treatments lamicarbazone

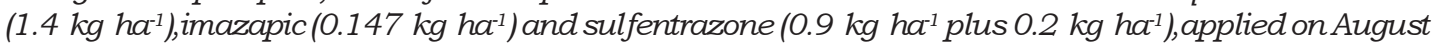
01, 2008 after sugarcane harvest, and one treatment without herbicide were tested. The herbicides used during the wet season were: mesotrione alone $\left(0.192 \mathrm{~kg} \mathrm{ha}^{-1}\right)$, and in mixture $\left(0.12 \mathrm{~kg} \mathrm{ha}^{-1}\right)$ with ametryn $\left(1.5 \mathrm{~kg} \mathrm{ha} \mathrm{h}^{-1}\right)$, atrazine $\left(1.5 \mathrm{~kg} \mathrm{ha}^{-1}\right)$ or diuron plus hexazinone $\left(0.702 \mathrm{plus} 0.198 \mathrm{~kg} \mathrm{ha}^{-1}\right)$, applied in postemergence on November 14, 2008, and two treatments without herbicide. The application of imazapic during the dry season was efficient for $\boldsymbol{E}$. heterophylla control, without the need of management complementation during the wet season. However, the amicarbazone and sulfentrazone treatments required mesotrione application, alone or mixed with ametryn, atrazine or diuron, plus
\end{abstract}

Recebido para publicação em 3.11.2009 e na forma revisada em 12.11.2010.

2 Prof., Dr., Dep. de Fitossanidade da Universidade Estadual Paulista - UNESP, Campus de Jaboticabal-SP, Via de Acesso Prof. Paulo Donato Castellane, s/n., 14.884-900 Jaboticabal-SP, Brasil, <correianm@fcav.unesp.br>; ${ }^{3}$ Usina Batatais, Batatais-SP, Brasil

Planta Daninha, Viçosa-MG, v. 28, n. 4, p. 853-863, 2010 
hexazinone to control $\boldsymbol{E}$. heterophylla during the wet season (105 to 230 days after application during the dry season). Without herbicide application during the dry season, mesotrione mixed with ametryn, atrazine or diuron plus hexazinone resulted in a better weed control than when applied alone. Despite the visual symptoms of phytointoxication caused by the treatments mesotrione plus ametryn and mesotrione plus (diuron plus hexazinone), none of the types of management adopted or combinations between them interfered in the number of viable stalk by linear meter, and in stalk diameter and height in sugarcane.

Keywords: herbicide combination, poinsettia, weed, mulch, Saccharum officinarum

\section{INTRODUÇÃO}

O controle químico de plantas daninhas é mais eficaz quando realizado durante a estação chuvosa, pois a água disponivel no solo e o intenso desenvolvimento das plantas daninhas favorecem a absorção dos herbicidas. No entanto, como nas regiões Sudeste e CentroOeste do Brasil a colheita de cana-de-açúcar inicia-se nos meses de abril/maio, estendendo-se até novembro/dezembro do ano agrícola, os produtores têm dificuldade em concentrar as aplicações de herbicidas somente na estação chuvosa, o que os leva a aplicá-los também no periodo de estiagem, a fim de que persistam no solo até o início da estação chuvosa (Azania et al., 2009).

Os herbicidas utilizados na época seca devem apresentar alta solubilidade em água e fraca ou moderada adsorção ao solo. Assim, mesmo numa condição de baixa umidade no solo, parte do produto será dessorvida para a solução e estará disponível para absorção pela radícula e/ou caulículo das plântulas. Entre os herbicidas registrados para a cultura de cana-de-açúcar, apenas amicarbazone, imazapic, hexazinone, isoxaflutole, sulfentrazone e tebuthiuron são recomendados para o uso na época seca, além da mistura comercial de clomazone + hexazinone (Rodrigues \& Almeida, 2005; Procópio et al., 2008; Agrofit, 2009). Esses herbicidas são classificados como de alta a extremamente alta solubilidade em água, hidrofilicos ou medianamente lipossolúveis, pouco ou não voláteis, fraca ou moderada adsorção ao solo (Vidal, 2002; Rodrigues \& Almeida, 2005).

No entanto, adaptados à aplicação de herbicidas na época seca, os produtores de cana têm-se deparado com algumas adversidades no controle de plantas daninhas nos últimos anos: primeiramente a palha, oriunda do corte mecanizado da cana-de-açúcar, que pode comprometer a capacidade do herbicida residual em atingir o solo, e, posteriormente, o aumento da infestação de espécies mais adaptadas à cobertura do solo, como Euphorbia heterophylla.

Dependendo das características físicoquímicas dos herbicidas, como solubilidade, pressão de vapor e polaridade, a palha terá maior ou menor influência na sua eficácia (Rodrigues, 1993). A quantidade e o período em que as chuvas ou irrigação ocorrem após a aplicação, além de mudanças na constituição química dos materiais vegetais em decomposição, também podem exercer grande influência na retenção dos herbicidas pela palha (Correia et al., 2007). Enquanto não ocorre a sua remoção da palha para o solo, o herbicida ficará exposto a perdas por fotodegradação, volatilização e até mesmo adsorção aos resíduos vegetais.

Independentemente do sistema de colheita da cana (com ou sem queimada), a dificuldade de manejo de E. heterophylla não está apenas na ineficácia de controle em pós-emergência, mas também na inibição de novos fluxos de emergência da planta daninha. $O$ controle químico dessa espécie em pré-emergência pode ser limitado pela capacidade de germinação das sementes e emergência das plântulas mesmo em profundidades maiores no perfil do solo. Segundo Kissmann \& Groth (1999), as sementes dessa espécie a menos de $4 \mathrm{~cm}$ de profundidade no perfil do solo germinam facilmente; entre 4 e $12 \mathrm{~cm}$ há gradual diminuição de germinação ou emergência; e abaixo de $12 \mathrm{~cm}$ ocorre pouca germinação e praticamente não há emergência. Esses resultados podem ser justificados pelos fatores luz e temperatura, uma vez que a germinação de sementes intactas de E. heterophylla a 
$25^{\circ} \mathrm{C}$ foi promovida pela luz, mas alterada quando o tegumento da semente foi removido, e as sementes tornaram-se indiferentes à luz (Suda \& Pereira, 1997). Salvador et al. (2007) também verificaram que as sementes desprovidas de tegumento foram indiferentes em relação à preferência de luz.

No sistema de colheita mecanizada sem queima da cana são observadas drásticas reduções na incidência de plantas daninhas, destacando-se as gramineas. Em contraste, têm sido verificadas altas infestações de E. heterophylla e Ipomoea spp. (Velini \& Negrisoli, 2000). A presença de palha de cana na superficie do solo em quantidades menores que 15 e $20 \mathrm{t} \mathrm{ha}^{-1}$ para E. heterophylla e Ipomoea spp., respectivamente, não afeta a emergência das plântulas dessas espécies (Martins et al., 1999; Correia \& Durigan, 2004). Contudo, em quantidades (15 e $20 \mathrm{t} \mathrm{ha}^{-1}$ ) maiores há redução de 70 a $60 \%$ na emergência de E. heterophylla (Monquero et al., 2007).

Com a hipótese de que o uso de herbicidas em cana-soca na época seca não é suficiente para a manutenção do controle de $E$. heterophylla, devendo ser complementado com a aplicação de herbicidas de ação residual na época úmida, objetivou-se estudar o efeito de herbicidas aplicados em pré e pósemergência, isolados e em combinações nas épocas seca e úmida, para o controle de E. heterophylla na cultura da cana-de-açúcar colhida mecanicamente sem queima prévia.

\section{MATERIAL E MÉTODOS}

O experimento foi desenvolvido no período de agosto de 2008 a junho de 2009, em área de produção comercial de cana-de-açúcar localizada no municipio de Jaboticabal-SP.

O delineamento experimental foi o de blocos ao acaso, com quatro repetições, em esquema de parcela subdividida. Nas parcelas foram estudados três herbicidas (pulverizados na época seca), além de testemunha sem aplicação, e nas subparcelas, as aplicações (em pós-emergência) de quatro herbicidas na época úmida e duas testemunhas sem herbicida: uma com a eliminação manual das plantas daninhas (testemunha capinada) e outra sem manejo químico ou manual (testemunha sem manejo).
Na época seca foram avaliados os herbicidas amicarbazone $\left(1.400 \mathrm{~g} \mathrm{ha}^{-1}\right)$, imazapic (147 $\mathrm{g} \mathrm{ha}^{-1}$ ) e sulfentrazone (900 $\mathrm{g} \mathrm{ha}^{-1}$ ), aplicados em pré-emergência após a colheita da cana. Os herbicidas utilizados na época úmida foram: mesotrione isolado (192 $\left.\mathrm{g} \mathrm{ha}^{-1}\right)$ e em mistura (120 $\mathrm{g} \mathrm{ha}^{-1}$ ) com ametryn (1.500 $\left.\mathrm{g} \mathrm{ha}^{-1}\right)$, atrazine $\left(1.500 \mathrm{~g} \mathrm{ha}^{-1}\right)$ ou diuron + hexazinone $\left(702+198 \mathrm{~g} \mathrm{ha}^{-1}\right)$. Em todas as caldas de mesotrione adicionou-se óleo mineral a $0,5 \% \mathrm{v} \mathrm{v}^{-1}$.

Cada parcela foi constituída de $6,0 \mathrm{~m}$ de largura (quatro linhas de cana) e $36,0 \mathrm{~m}$ de comprimento, totalizando $216,0 \mathrm{~m}^{2}$. Dentro delas, foram demarcadas as subparcelas, com 6,0 m de largura e 6,0 m de comprimento.

A variedade de cana RB 855453 (6 $6^{\circ}$ corte) foi colhida mecanicamente no dia $24 / 7 / 2008$, com a manutenção de $14,85 \mathrm{t} \mathrm{ha}^{-1}$ de palha sobre o solo.

$\mathrm{Na}$ época seca, os herbicidas foram aplicados em 1/8/2008, com o auxílio de pulverizador costal à pressão constante (mantida por $\mathrm{CO}_{2}$ comprimido) de $3,0 \mathrm{kgf} \mathrm{cm}^{-2}$, munido de barra com seis pontas de pulverização de jato plano XR 11002 , espaçadas de $0,5 \mathrm{~m}$, e com consumo de calda equivalente a $200 \mathrm{~L} \mathrm{ha}^{-1}$. $\mathrm{Na}$ época úmida, a aplicação foi realizada em 14/11/2008, 113 dias após o corte da cana e com 12,03 t ha ${ }^{-1}$ de palha sobre o solo. Devido ao porte da cana, a pulverização foi dirigida, localizada na entrelinha da cultura, procurando-se atingir unicamente as plantas daninhas, sem a ocorrência de possivel efeito guardachuva das plantas de cana. Para essa aplicação, foi utilizado pulverizador costal, à pressão constante (mantida pelo $\mathrm{CO}_{2}$ comprimido) de $4,0 \mathrm{kgf} \mathrm{cm}^{-2}$, munido de barra com duas pontas de pulverização de jato plano TT 11002 , espaçadas de 0,75 m, e com consumo de calda equivalente a $200 \mathrm{~L} \mathrm{ha}^{-1}$. No momento das aplicações, foram registrados os valores de temperatura do ar, umidade relativa do ar e velocidade dos ventos (Tabela 1).

Na segunda aplicação de herbicidas, as plantas de cana tinham $95 \mathrm{~cm}$ de altura média do dossel, e as de E. heterophylla, de 17,94 a $24,6 \mathrm{~cm}$. Na Tabela 2 são apresentados o número de folhas por planta, a altura de plantas, a porcentagem de cobertura e a densidade de plantas de $E$. heterophylla para cada manejo adotado na época seca.

Planta Daninha, Viçosa-MG, v. 28, n. 4, p. 853-863, 2010 
Tabela 1 - Temperatura do ar, umidade relativa do ar e velocidade do vento no início e final das aplicações dos herbicidas, além das datas e horários das pulverizações e umidade do solo. Jaboticabal-SP. 2008/09

\begin{tabular}{|l|c|c|c|c|c|c|}
\hline \multicolumn{1}{|c|}{ Aplicação } & Data & Horário & $\begin{array}{c}\text { Temperatura } \\
\left({ }^{\circ} \mathrm{C}\right)\end{array}$ & $\begin{array}{c}\text { Umidade do ar } \\
(\%)\end{array}$ & $\begin{array}{c}\text { Vento } \\
\left(\mathrm{km} \mathrm{h}^{-1}\right)\end{array}$ & $\begin{array}{c}\text { Umidade do } \\
\text { solo }\end{array}$ \\
\hline Época seca & $01 / 08 / 2008$ & $7 \mathrm{~h} 30-9 \mathrm{~h} 55$ & $19,3-30,5$ & $68-46$ & $6,1-10,1$ & Seco \\
\hline Época úmida & $14 / 11 / 2008$ & $8 \mathrm{~h} 25-10 \mathrm{~h} 45$ & $24,9-31,6$ & $77-49$ & $4,5-5,7$ & Úmido \\
\hline
\end{tabular}

Tabela 2 - Número de folhas por planta, altura de plantas, porcentagem de cobertura e densidade de plantas por $\mathrm{m}^{2}$ de E.heterophylla no momento da aplicação dos herbicidas na época úmida, para cada manejo adotado na seca. Jaboticabal-SP. 2008/09

\begin{tabular}{|l|c|c|c|c|}
\hline \multicolumn{1}{|c|}{ Manejo na época seca } & $\begin{array}{c}\mathrm{N}^{\mathrm{o}} \text { de folhas } \\
\text { (unidade por planta) }\end{array}$ & $\begin{array}{c}\text { Altura } \\
(\mathrm{cm})\end{array}$ & Cobertura (\%) & $\begin{array}{c}\text { Densidade } \\
\left(\mathrm{plantas}^{-2}\right)\end{array}$ \\
\hline Amicarbazone & 10,93 & 23,18 & 25,00 & 2,61 \\
\hline Imazapic & 6,12 & 17,94 & 5,00 & 1,28 \\
\hline Sulfentrazone & 11,71 & 23,75 & 25,00 & 2,95 \\
\hline Tratamento sem herbicida & 11,50 & 24,60 & 25,00 & 2,04 \\
\hline
\end{tabular}

A comunidade infestante da área experimental foi composta unicamente por E. heterophylla.

Os valores de precipitação e temperatura do ar mínima e máxima registrados no período de julho de 2008 a junho de 2009 estão apresentados na Figura 1.

Aos 11, 17 e 30 dias após a aplicação dos herbicidas na época seca $\left(\mathrm{DAA}_{\mathrm{HS}}\right)$ foram avaliados os sintomas visuais de intoxicação nas plantas de cana, por meio da escala de notas de 0 a $100 \%$, em que zero representa a ausência de injúrias visuais e 100 a morte da planta (SBCPD, 1995).

Aos 11, 17, 30, 45, 60, 75, 90 e 104 dias após a aplicação dos herbicidas na época seca $\left(\mathrm{DAA}_{\mathrm{HS}}\right)$, foram realizadas as contagens do número de plantas emergidas de $E$. heterophylla em 12 pontos de $1,0 \mathrm{~m}^{2}$ cada, escolhidos aleatoriamente dentro da área útil de cada parcela $\left(105,0 \mathrm{~m}^{2}\right)$.

$\mathrm{Na}$ época úmida, aos 15, 30, 60, 95 e 125 dias após a aplicação dos herbicidas $\left(\mathrm{DAA}_{\mathrm{HU}}\right)$ foram realizadas avaliações visuais de controle, por meio da escala de notas de 0 a $100 \%$, em que zero representa a ausência de intoxicação visual e 100 a morte da planta.
Aos 7, 15, 30 e $45 \mathrm{DAA}_{\mathrm{HU}}$ foram avaliadas possiveis injúrias visuais nas plantas de cana, atribuindo-se notas em porcentagens (SBCPD, 1995).

As notas de controle foram estabelecidas em função da testemunha mantida infestada durante todo o período experimental, representada pela subparcela sem aplicação de herbicida nas épocas seca e úmida.

Aos 15, 30, 45 e $60 \mathrm{DAA}_{\mathrm{HU}}$ foram realizadas as contagens do número de plantas de $E$. heterophylla emergidas na área útil $\left(15,0 \mathrm{~m}^{2}\right)$ de cada subparcela.

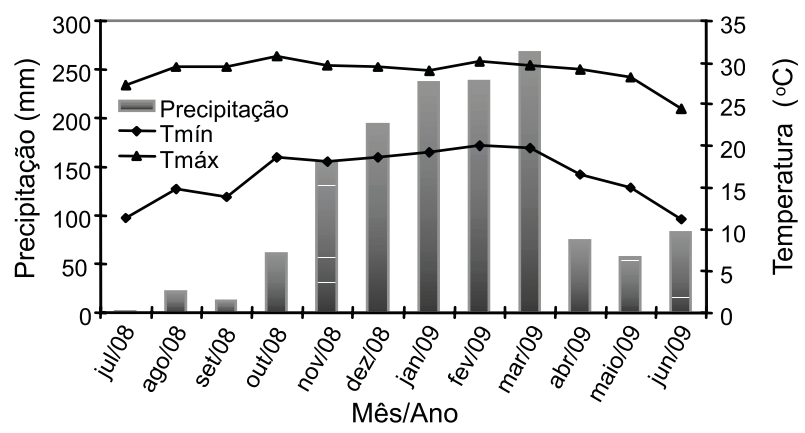

Figura 1 - Precipitação e temperaturas do ar mínima e máxima registradas no período de julho de 2008 a junho de 2009 em Estação Agroclimatológica localizada a $15 \mathrm{~km}$ do experimento. Jaboticabal-SP. 2008/2009 
Aos 328 dias após a colheita da cana, foi feita a contagem do número de colmos viáveis em quatro metros lineares, assim como a medição da altura e do diâmetro de 10 colmos de cana dentro da área útil de cada subparcela.

Os resultados foram submetidos à análise de variância, empregando-se o teste F. Os efeitos dos manejos nas épocas seca e úmida, quando significativos, foram comparados pelo teste de Tukey a $5 \%$ de probabilidade. As interações, quando significativas, foram desdobradas, e as médias, comparadas pelo teste de Tukey a $5 \%$ de probabilidade. Os dados referentes ao número de plantas de E. heterophylla na época seca não foram submetidos à análise estatística.

\section{RESULTADOS E DISCUSSÃO}

Os herbicidas pulverizados na época seca não ocasionaram nenhuma injúria visual às plantas de cana.

No período de 11 a 61 dias após aplicação dos herbicidas (em 1/8/2008) não foi observada emergência de $E$. heterophylla nas parcelas, inclusive naquelas da testemunha sem manejo químico na época seca (Figura 2). Somente a partir de outubro, com o aumento da disponibilidade de água no solo, de acordo com os índices pluviométricos registrados no período (Figura 1), constatou-se emergência da planta daninha na área experimental. No momento da aplicação dos herbicidas na época úmida, houve maior número de plântulas nas parcelas pulverizadas com sulfentrazone, com 2,9 plantas $\mathrm{m}^{-2}$, seguido de amicarbazone $\left(2,6\right.$ plantas $\left.\mathrm{m}^{-2}\right)$, testemunha sem herbicida (2,0 plantas $\left.\mathrm{m}^{-2}\right)$ e imazapic $\left(1,2\right.$ planta $\left.\mathrm{m}^{-2}\right)$. Nas parcelas pulverizadas com imazapic, as plantas de $E$. heterophylla apresentavam altura média de $17,94 \mathrm{~cm}$ e ocupavam apenas $5,0 \%$ da área (Tabela 2). Quanto aos demais tratamentos de seca, os valores médios foram de $23,84 \mathrm{~cm}$ de altura de plantas e $25 \%$ de porcentagem de cobertura.

Azania et al. (2009) verificaram que os herbicidas amicarbazone $\left(1.050 \mathrm{~g} \mathrm{ha}^{-1}\right) \mathrm{e}$ sulfentrazone (600 $\mathrm{g} \mathrm{ha}^{-1}$ ) promoveram controle inferior de E. heterophylla, com médias de $66,67 \%$ e $76,67 \%$, respectivamente, comparados ao imazapic $\left(122,5 \mathrm{~g} \mathrm{ha}^{-1}\right)$, com $90,83 \%$, aos 150 dias após a aplicação em préemergência na época seca (em 1/8/2007). No entanto, em condições de vasos com $5 \mathrm{t} \mathrm{ha}^{-1}$ de palha de cana sobre o solo e simulação de $30 \mathrm{~mm}$ de chuva 24 horas após a pulverização, Toledo et al. (2009) mencionaram que o amicarbazone (525, 700, 875 e $\left.1.050 \mathrm{~g} \mathrm{ha}^{-1}\right)$ aplicado em pré-emergência foi eficaz no controle de E. heterophylla, independentemente da dose estudada. No presente trabalho, assim como no de Azania et al. (2009), o desempenho do amicarbazone pode ter sido desfavorecido pela aplicação em condição de baixa umidade do solo (época seca).

A interação manejo na época seca $x$ manejo na época úmida foi significativa para todas as épocas de avaliação visual de controle (Tabela 3). Aos $15 \mathrm{DAA}_{\mathrm{HU}}$ para amicarbazone, sulfentrazone e testemunha sem herbicida na seca, não houve diferença significativa entre os herbicidas aplicados na época úmida, os quais diferiram apenas da testemunha sem manejo na época úmida (Tabela 4). Para imazapic, os tratamentos estudados na época úmida não diferiram entre si. Esse fato indica que, quando foi utilizado imazapic na época seca, a aplicação de mesotrione, isolado ou em mistura, no periodo chuvoso foi desnecessária. Ao contrário, nas parcelas de amicarbazone e sulfentrazone, para o controle satisfatório (acima de $85 \%$ ) de $E$. heterophylla na época úmida, foi necessária a complementação com outros herbicidas. Nesse caso, a aplicação de herbicidas na época seca não foi suficiente para a manutenção do controle da planta daninha até a época chuvosa.

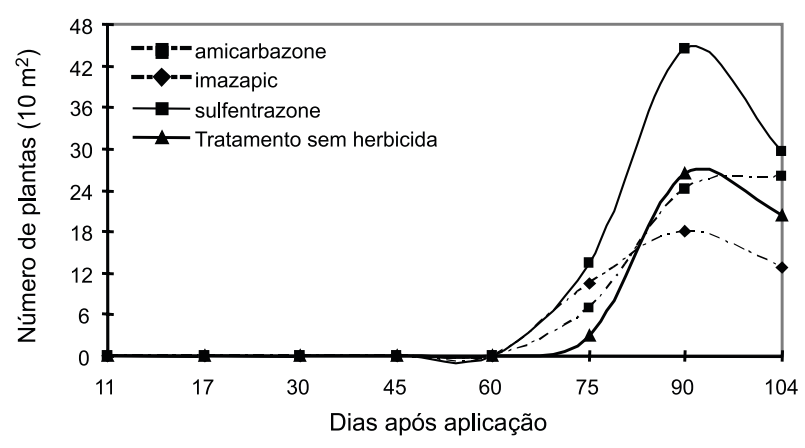

Figura 2 - Dinâmica da emergência de Euphorbia heterophylla após a aplicação de herbicidas na época seca. JaboticabalSP. 2008/09. 
Tabela 3 - Resultados do teste F da análise de variância para porcentagem de controle de Euphorbia heterophylla aos 15, 30, 60, 95 e 125 dias após a aplicação de herbicidas na época úmida $\left(\mathrm{DAA}_{\mathrm{HU}}\right)$ e número de plantas emergidas aos $15,30,45$ e $60 \mathrm{DAA}_{\mathrm{HU}}$ Jaboticabal-SP. 2008/2009

\begin{tabular}{|l|c|c|c|c|c|c|c|c|c|}
\hline \multirow{2}{*}{ Fonte de variação } & \multicolumn{4}{|c|}{ Controle - DAA $\mathrm{HU}_{\mathrm{HU}}$} & \multicolumn{4}{c|}{ Número de plantas - $\mathrm{DAA}_{\mathrm{HU}}$} \\
\cline { 2 - 10 } & 15 & 30 & 60 & 95 & 125 & 15 & 30 & 45 & 60 \\
\hline Tratamentos de seca & $41,02^{* *}$ & $14,71^{* *}$ & $44,48^{* *}$ & $22,72^{* *}$ & $27,81^{* *}$ & 0,61 & 0,95 & 0,94 & 0,56 \\
\hline Tratamentos de úmida & $321,33^{* *}$ & $50,32^{* *}$ & $122,07^{* *}$ & $74,88^{* *}$ & $76,70^{* *}$ & $3,05^{*}$ & $6,35^{* *}$ & 2,27 & $4,44^{* *}$ \\
\hline Trat. seca x Trat. úmida & $29,44^{* *}$ & $3,70^{* *}$ & $13,04^{* *}$ & $7,53^{* *}$ & $7,81^{* *}$ & 0,48 & 1,64 & 0,70 & 0,88 \\
\hline Bloco & $4,71^{*}$ & $9,55^{* *}$ & $11,12^{* *}$ & $8,16^{* *}$ & $8,85^{* *}$ & $4,56^{*}$ & 2,64 & $5,66^{*}$ & $5,54^{* *}$ \\
\hline CV 1 (\%) & 7,42 & 14,36 & 8,19 & 13,01 & 11,78 & 49,99 & 44,69 & 35,74 & 68,00 \\
\hline CV 2 (\%) & 7,71 & 19,41 & 10,88 & 15,55 & 15,36 & 69,42 & 58,72 & 56,63 & 71,17 \\
\hline
\end{tabular}

**, * Significativo a $1 \%$ e $5 \%$ de probabilidade, respectivamente, pelo teste $\mathrm{F}$ da análise de variância

Tabela 4 - Porcentagem de controle de Euphorbia heterophylla aos 15 dias após a aplicação de herbicidas na época úmida. JaboticabalSP. 2008/2009

\begin{tabular}{|c|c|c|c|c|}
\hline \multirow[b]{2}{*}{ Manejo na época úmida } & \multicolumn{4}{|c|}{ Manejo na época seca } \\
\hline & Amicarbazone & Imazapic & Sulfentrazone & $\begin{array}{c}\text { Testemunha sem } \\
\text { herbicida }\end{array}$ \\
\hline Mesotrione & $91,25 \mathrm{a} \mathrm{A}^{1 / \prime}$ & 97,50 a $\mathrm{A}$ & 93,75 a A & 87,50 a $\mathrm{A}$ \\
\hline Mesotrione + ametryn & 99,25 a A & $100,00 \mathrm{a} \mathrm{A}$ & 100,00 a $\mathrm{A}$ & 98,75 a $\mathrm{A}$ \\
\hline Mesotrione + atrazine & 100,00 a A & 100,00 a $\mathrm{A}$ & 100,00 a $\mathrm{A}$ & 100,00 a $\mathrm{A}$ \\
\hline Mes.+(diuron+hexazinone) & 100,00 a A & $100,00 \mathrm{a} \mathrm{A}$ & 96,25 a $\mathrm{A}$ & 96,25 a $\mathrm{A}$ \\
\hline 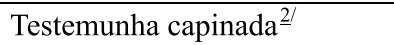 & 100,00 a $\mathrm{A}$ & 100,00 a $\mathrm{A}$ & 100,00 a $\mathrm{A}$ & 100,00 a $\mathrm{A}$ \\
\hline Testemunha sem manejo & $10,00 \mathrm{~b} \mathrm{~B}$ & 92,50 a $\mathrm{A}$ & $0,00 \mathrm{~b} B$ & $0,00 \mathrm{~b} B$ \\
\hline DMS (linha) & \multicolumn{4}{|c|}{12,26} \\
\hline DMS (coluna) & \multicolumn{4}{|c|}{13,79} \\
\hline
\end{tabular}

${ }^{1 /}$ Com base no teste de Tukey a 5\% de probabilidade, médias seguidas de letra minúscula, nas colunas, comparam os tratamentos da época úmida dentro de cada manejo na época seca, e letras maiúsculas, nas linhas, comparam os quatro manejos na seca para cada tratamento da época úmida. 느 Testemunha capinada apenas no dia da pulverização dos herbicidas na época úmida.

Isso também foi evidenciado aos 30, 60, 95 e $125 \mathrm{DAA}_{\mathrm{HU}}$, cujos resultados são apresentados nas Tabelas $5,6,7$ e 8 , respectivamente. Nessas avaliações, para amicarbazone e sulfentrazone todos os herbicidas aplicados na época úmida foram eficazes no controle de $E$. heterophylla, diferindo apenas da testemunha sem manejo no período chuvoso. O controle observado nas parcelas pulverizadas unicamente com amicarbazone e sulfentrazone, sem complementação de manejo na época úmida, foi inferior a $35 \%$, sendo classificado como nenhum, segundo ALAM (1974). Entretanto, quando foi pulverizado o herbicida imazapic, a testemunha sem manejo na época úmida não diferiu dos demais tratamentos. Para a aplicação única de imazapic, o controle variou de $80,75 \%$ a 93,75\%, o qual é considerado de bom a muito bom (ALAM, 1974). Para a testemunha sem herbicida na seca, as maiores porcentagens de controle da planta daninha foram obtidas com a pulverização de mesotrione + ametryn e mesotrione + (diuron + hexazinone) aos 30, 95 e $125 \mathrm{DAA}_{\mathrm{HU}}$, diferindo de mesotrione isolado e testemunha sem manejo na época úmida.

Monquero et al. (2009) relataram que o herbicida mesotrione (192 $\mathrm{g} \mathrm{ha}^{-1}$ ) aplicado em plantas de E. heterophylla com seis folhas definitivas resultou em $85 \%$ de controle, aos 90 DAA. Contudo, a sua associação ao ametryn $\left(120+1.500 \mathrm{~g} \mathrm{ha}^{-1}\right)$ ou trifloxysulfuron + ametryn $\left[120+(27,77+1,097) \mathrm{g} \mathrm{ha}^{-1}\right]$ controlou $100 \%$ das plantas. No presente estudo, quando não foi realizado o manejo químico de 
Tabela 5 - Porcentagem de controle de Euphorbia heterophylla aos 30 dias após a aplicação de herbicidas na época úmida. JaboticabalSP. 2008/2009

\begin{tabular}{|c|c|c|c|c|}
\hline \multirow[b]{2}{*}{ Manejo na época úmida } & \multicolumn{4}{|c|}{ Manejo na época seca } \\
\hline & Amicarbazone & Imazapic & Sulfentrazone & $\begin{array}{c}\text { Tratamento sem } \\
\text { herbicida }\end{array}$ \\
\hline Mesotrione & $82,50 \mathrm{a} \mathrm{AB}^{1 / 1}$ & 96,25 a $\mathrm{A}$ & 85,00 a $\mathrm{AB}$ & $65,00 \mathrm{~b} \quad \mathrm{~B}$ \\
\hline Mesotrione + ametryn & $95,00 \mathrm{a} \mathrm{A}$ & 96,25 a $\mathrm{A}$ & 95,00 a $\mathrm{A}$ & $100,00 \mathrm{a} \mathrm{A}$ \\
\hline Mesotrione + atrazine & 100,00 a A & 100,00 a $\mathrm{A}$ & 99,25 a $\mathrm{A}$ & $96,25 \mathrm{ab} A$ \\
\hline Mes.+(diuron+hexazinone) & 99,25 a A & 100,00 a $\mathrm{A}$ & 92,50 a $\mathrm{A}$ & 98,75 a $A$ \\
\hline Testemunha capinada $^{\underline{2} /}$ & 85,00 a A & 95,00 a $\mathrm{A}$ & 74,50 a $\mathrm{A}$ & $92,50 \mathrm{ab} \mathrm{A}$ \\
\hline Testemunha sem manejo & $15,00 \mathrm{~b} \mathrm{~B}$ & 80,75 a $\mathrm{A}$ & $7,50 \mathrm{~b} B$ & $0,00 \mathrm{c} \quad \mathrm{B}$ \\
\hline DMS (linha) & \multicolumn{4}{|c|}{28,27} \\
\hline DMS (coluna) & \multicolumn{4}{|c|}{32,86} \\
\hline
\end{tabular}

${ }^{1 /}$ Com base no teste de Tukey a 5\% de probabilidade, médias seguidas de letra minúscula, nas colunas, comparam os tratamentos da época úmida dentro de cada manejo na época seca, e letras maiúsculas, nas linhas, comparam os quatro manejos na seca para cada tratamento da época úmida. $\stackrel{2}{2}$ Testemunha capinada apenas no dia da pulverização dos herbicidas na época úmida.

Tabela 6 - Porcentagem de controle de Euphorbia heterophylla aos 60 dias após a aplicação de herbicidas na época úmida. JaboticabalSP. 2008/2009

\begin{tabular}{|c|c|c|c|c|}
\hline \multirow[b]{2}{*}{ Manejo na época úmida } & \multicolumn{4}{|c|}{ Manejo na época seca } \\
\hline & Amicarbazone & Imazapic & Sulfentrazone & $\begin{array}{c}\text { Tratamento sem } \\
\text { herbicida }\end{array}$ \\
\hline Mesotrione & $91,25 \mathrm{a} \mathrm{AB}^{1 /}$ & 97,50 a $\mathrm{A}$ & 86,25 a $\mathrm{AB}$ & $78,75 \mathrm{~b} \quad \mathrm{~B}$ \\
\hline Mesotrione + ametryn & $96,25 \mathrm{a} \mathrm{A}$ & $96,25 \mathrm{a} \mathrm{A}$ & 95,00 a $\mathrm{A}$ & $100,00 \mathrm{a} \quad \mathrm{A}$ \\
\hline Mesotrione + atrazine & $100,00 \mathrm{a} \mathrm{A}$ & 100,00 a $\mathrm{A}$ & 98,75 a $\mathrm{A}$ & $95,00 \mathrm{ab} \mathrm{A}$ \\
\hline Mes.+(diuron+hexazinone) & 97,50 a $\mathrm{A}$ & $100,00 \mathrm{a} \mathrm{A}$ & 92,50 a $\mathrm{A}$ & $97,50 \mathrm{ab} \mathrm{A}$ \\
\hline Testemunha capinada $^{2 /}$ & 91,25 a A & 98,12 a $\mathrm{A}$ & 90,00 a $\mathrm{A}$ & $91,25 \mathrm{ab} A$ \\
\hline Testemunha sem manejo & $35,00 \mathrm{~b} \mathrm{~B}$ & 92,60 a $\mathrm{A}$ & $5,00 \mathrm{~b} \mathrm{C}$ & $0,00 \mathrm{c} \quad \mathrm{C}$ \\
\hline DMS (linha) & \multicolumn{4}{|c|}{16,48} \\
\hline DMS (coluna) & \multicolumn{4}{|c|}{19,13} \\
\hline
\end{tabular}

1/ Com base no teste de Tukey a 5\% de probabilidade, médias seguidas de letra minúscula, nas colunas, comparam os tratamentos da época úmida dentro de cada manejo na época seca, e letras maiúsculas, nas linhas, comparam os quatro manejos na seca para cada tratamento da época úmida. ${ }^{2 /}$ Testemunha capinada apenas no dia da pulverização dos herbicidas na época úmida.

Tabela 7 - Porcentagem de controle de Euphorbia heterophyllla aos 95 dias após a aplicação de herbicidas na época úmida. JaboticabalSP. 2008/2009

\begin{tabular}{|c|c|c|c|c|}
\hline \multirow[b]{2}{*}{ Manejo na época úmida } & \multicolumn{4}{|c|}{ Manejo na época seca } \\
\hline & Amicarbazone & Imazapic & Sulfentrazone & $\begin{array}{c}\text { Tratamento sem } \\
\text { herbicida }\end{array}$ \\
\hline Mesotrione & $85,00 \mathrm{a} \mathrm{AB}^{1 /}$ & 97,50 a $\mathrm{A}$ & $82,50 \mathrm{a} A B$ & $68,75 \mathrm{~b} \quad \mathrm{~B}$ \\
\hline Mesotrione + ametryn & $96,25 \mathrm{a} \mathrm{A}$ & 96,25 a A & $93,75 \mathrm{aA}$ & $96,25 \mathrm{a} \quad \mathrm{A}$ \\
\hline Mesotrione + atrazine & 100,00 a $\mathrm{A}$ & 100,00 a $\mathrm{A}$ & 100,00 a A & $92,50 \mathrm{ab} A$ \\
\hline Mes.+(diuron+hexazinone) & 100,00 a A & 99,38 a $\mathrm{A}$ & 91,25 a A & 96,50 a $\mathrm{A}$ \\
\hline Testemunha capinada ${ }^{2 /}$ & 93,75 a A & 98,75 a $\mathrm{A}$ & 93,25 a A & $92,50 \mathrm{ab} A$ \\
\hline Testemunha sem manejo & $13,75 \mathrm{~b} \mathrm{~B}$ & 93,75 a $A$ & $0,00 \mathrm{~b} \mathrm{~B}$ & $0,00 \mathrm{c} \quad \mathrm{B}$ \\
\hline DMS (linha) & \multicolumn{4}{|c|}{23,31} \\
\hline DMS (coluna) & \multicolumn{4}{|c|}{26,74} \\
\hline
\end{tabular}

${ }^{1 /}$ Com base no teste de Tukey a $5 \%$ de probabilidade, médias seguidas de letra minúscula, nas colunas, comparam os tratamentos da época úmida dentro de cada manejo na época seca, e letras maiúsculas, nas linhas, comparam os quatro manejos na seca para cada tratamento da época úmida. $\stackrel{2 /}{2}$ Testemunha capinada apenas no dia da pulverização dos herbicidas na época úmida. 
Tabela 8 - Porcentagem de controle de Euphorbia heterophylla aos 125 dias após a aplicação de herbicidas na época úmida, com ou sem manejo prévio da planta daninha na época seca. Jaboticabal-SP. 2008/2009

\begin{tabular}{|c|c|c|c|c|}
\hline \multirow[b]{2}{*}{ Manejo na época úmida } & \multicolumn{4}{|c|}{ Manejo na época seca } \\
\hline & Amicarbazone & Imazapic & Sulfentrazone & $\begin{array}{c}\text { Tratamento sem } \\
\text { herbicida }\end{array}$ \\
\hline Mesotrione & $85,00 \mathrm{a} \mathrm{AB}^{1 /}$ & 97,00 a $\mathrm{A}$ & 85,00 a $\mathrm{AB}$ & $67,50 \mathrm{~b} \quad \mathrm{~B}$ \\
\hline Mesotrione + ametryn & 95,00 a A & 96,00 a $\mathrm{A}$ & 93,75 a A & 97,50 a $\mathrm{A}$ \\
\hline Mesotrione + atrazine & $100,00 \mathrm{a} \mathrm{A}$ & 100,00 a $\mathrm{A}$ & $100,00 \mathrm{a} \mathrm{A}$ & $92,50 \mathrm{ab} \mathrm{A}$ \\
\hline Mes.+(diuron+hexazinone) & 100,00 a A & 99,38 a $\mathrm{A}$ & $91,25 \mathrm{a} \mathrm{A}$ & 96,50 a $\mathrm{A}$ \\
\hline Testemunha capinada ${ }^{\underline{2} /}$ & 93,75 a A & 99,38 a $\mathrm{A}$ & 92,50 a A & $91,88 \mathrm{ab} \mathrm{A}$ \\
\hline Testemunha sem manejo & $13,75 \mathrm{~b} \mathrm{~B}$ & 93,75 a $\mathrm{A}$ & $0,00 \mathrm{~b} \mathrm{~B}$ & $0,00 \mathrm{c} B$ \\
\hline DMS (linha) & \multicolumn{4}{|c|}{22,79} \\
\hline DMS (coluna) & \multicolumn{4}{|c|}{26,39} \\
\hline
\end{tabular}

${ }^{1 /}$ Com base no teste de Tukey a 5\% de probabilidade, médias seguidas de letra minúscula, nas colunas, comparam os tratamentos da época úmida dentro de cada manejo na época seca, e letras maiúsculas, nas linhas, comparam os quatro manejos na seca para cada tratamento da época úmida. ${ }^{2 /}$ Testemunha capinada apenas no dia da pulverização dos herbicidas na época úmida.

E. heterophylla na época seca, no momento da aplicação dos herbicidas no período chuvoso as plantas daninhas tinham maior altura $(24,6 \mathrm{~cm})$ e número de folhas $(11,5)$ do que na pesquisa descrita anteriormente, o que pode ter contribuído para obtenção de menor porcentagem de controle $(67,50 \%$ aos $125 \mathrm{DAA}_{\mathrm{HU}}$ ) quando utilizado mesotrione isoladamente.

Como foi observado aos $15 \mathrm{DAA}_{\mathrm{HU}}$, sem a complementação de manejo na época úmida, o herbicida imazapic ocasionou as maiores notas de controle, diferindo dos demais tratamentos de seca (Tabelas 5, 6, 7 e 8). Não houve reinfestação da planta daninha nas parcelas, e o controle observado aos $125 \mathrm{DAA}_{\mathrm{HU}}$ mantevese até a colheita.

De modo geral, houve pequeno aumento nas notas de controle a partir da avaliação realizada aos $60 \mathrm{DAA}_{\mathrm{HU}}$, possivelmente pelo fechamento do dossel e sombreamento da área pelas plantas de cana-de-açúcar, além da morte de algumas plantas de E. heterophylla, devido ao fim do ciclo biológico destas. O ciclo entre a emergência e a frutificação de E. heterophylla é curto, de modo que podem ocorrer de duas a quatro gerações no período de um ano (Kissmann \& Groth, 1999). Nesse estudo foi observada apenas uma geração de E. heterophylla. A incorporação das sementes produzidas no banco de sementes do solo foi variável com o manejo adotado em cada tratamento. Essa "chuva de sementes" ocorreu nos tratamentos que obtiveram notas de controle inferiores a 70\%, como amicarbazone e sulfentrazone sem complementação de manejo na época úmida, mesotrione isolado sem manejo prévio no período de estiagem e testemunha sem manejo nas épocas seca e úmida.

Quanto à dinâmica de emergência de E. heterophylla avaliada após a aplicação dos herbicidas na época úmida, a interação entre os manejos não foi significativa para nenhuma época de avaliação (Tabela 3). Para os fatores isolados, houve efeito significativo dos herbicidas pulverizados na época úmida sobre o número de plantas de $E$. heterophylla aos 15, 30 e $60 \mathrm{DAA}_{\mathrm{HU}}$, ao contrário dos manejos avaliados na seca, que não foram significativos para nenhuma época de avaliação.

Aos $15 \mathrm{DAA}_{\mathrm{HU}}$, independentemente do manejo adotado na época seca, houve menor número de plântulas de $E$. heterophylla com a aplicação de mesotrione + atrazine, diferindo apenas da testemunha capinada (Tabela 9). Na avaliação seguinte (30 DAA $\mathrm{HU}_{\mathrm{U}}$ ), os tratamentos de herbicidas não diferiram entre si, e sim da testemunha capinada. Aos $45 \mathrm{DAA}_{\mathrm{HU}}$, não houve diferença significativa entre os tratamentos. Aos $60 \mathrm{DAA}_{\mathrm{HU}}$, a aplicação de mesotrione, isolado e em mistura, resultou em menor emergência de $E$. heterophylla. Isso evidencia o efeito residual dos herbicidas pulverizados 
na época úmida no controle de novos fluxos de emergência de E. heterophylla nas parcelas, inclusive naquelas pulverizadas com mesotrione isolado.

Entretanto, o número de plântulas emergidas após a aplicação de herbicida na época úmida foi pouco expressivo, menos de 0,27 planta por $\mathrm{m}^{2}$. A germinação de sementes intactas (com tegumento) de E. heterophylla é promovida pela luz (Suda \& Pereira, 1997); portanto, o fechamento do dossel das plantas de cana e o sombreamento da área podem ter desfavorecido a germinação e, consequentemente, a emergência de novas plântulas nas parcelas, inclusive nas parcelas da testemunha capinada (tratamento sem ação residual). Quando os herbicidas foram aplicados na época úmida (105 dias após a aplicação dos herbicidas na seca), não havia ocorrido o pleno fechamento e sombreamento das entrelinhas

Tabela 9 - Número de plantas (em $15 \mathrm{~m}^{2}$ ) de Euphorbia heterophylla emergidas aos 15,30, 45 e 60 dias após a aplicação de herbicidas na época úmida. Jaboticabal-SP. $2008 / 2009$

\begin{tabular}{|l|l|c|c|c|}
\hline \multirow{2}{*}{ Manejo na época úmida } & \multicolumn{4}{|c|}{ Dias após a aplicação } \\
\cline { 2 - 5 } & \multicolumn{1}{|c|}{15} & 30 & 45 & 60 \\
\hline Mesotrione & $0,06 \mathrm{ab}^{\mathrm{1}}$ & $0,56 \mathrm{a}$ & 0,88 & $0,62 \mathrm{a}$ \\
\hline Mesotrione + ametryn & $0,44 \mathrm{ab}$ & $1,66 \mathrm{a}$ & 0,69 & $0,69 \mathrm{a}$ \\
\hline Mesotrione + atrazine & $0,00 \mathrm{a}$ & $0,44 \mathrm{a}$ & 0,75 & $0,62 \mathrm{a}$ \\
\hline Mes.+(diuron+hexazinone) & $0,12 \mathrm{ab}$ & $0,44 \mathrm{a}$ & 0,75 & $0,75 \mathrm{a}$ \\
\hline Testemunha capinada & $0,81 \mathrm{~b}$ & $3,69 \mathrm{~b}$ & 2,38 & $2,94 \mathrm{~b}$ \\
\hline DMS & $0,81 \mathrm{~b}$ & 2,22 & 1,92 & 1,93 \\
\hline
\end{tabular}

${ }^{1 /}$ Médias seguidas da mesma letra não diferem significativamente entre si pelo teste de Tukey a 5\% de probabilidade. ${ }^{2 /}$ Testemunha capinada apenas no dia da pulverização dos herbicidas na época úmida. de cana. Os fatores luz e temperatura adequados e o aumento da disponibilidade hídrica no solo podem ter contribuído para a promoção de condições ideais para a germinação das sementes e o crescimento da planta daninha de outubro a novembro, antes da aplicação dos herbicidas na época úmida.

Para todos os tratamentos estudados, as novas plântulas emergidas na área experimental não ocasionaram aumento no banco de sementes da planta daninha no solo, pois a maioria delas morreu e as sobreviventes não frutificaram, em razão do total sombreamento da área. Dessa forma, o uso de herbicidas no período chuvoso foi importante para a eliminação das plantas emergidas de outubro a novembro nas parcelas e não na inibição de novos fluxos de emergência após a aplicação.

Quanto às características avaliadas nas plantas de cana, os tratamentos mesotrione + ametryn e mesotrione + (diuron + hexazinone) promoveram injúrias visuais classificadas como moderadas (de $18 \%$ e $30 \%$ aos $7 \mathrm{DAA}_{\mathrm{HU}}$, respectivamente), que desapareceram completamente aos 45 DAA (Tabelas 10 e 11). A aplicação de mesotrione isolado e em mistura com atrazine não ocasionou danos visíveis às plantas de cana. No entanto, apesar de terem sido observadas variações nas avaliações de fitointoxicação e controle de E. heterophylla, nenhum dos tratamentos avaliados afetou negativamente o diâmetro e altura de colmos, assim como o número de colmos viáveis por metro linear (Tabelas 10 e 12).

Os resultados permitiram concluir que a aplicação de imazapic na época seca foi eficaz no controle de $E$. heterophylla, dispensando a

Tabela 10 - Resultados do teste F da análise de variância para notas de fitointoxicação na cana-de-açúcar aos 7, 15, 30 e 45 dias após a aplicação de herbicidas na época úmida $\left(\mathrm{DAA}_{\mathrm{HU}}\right)$, número de colmos viáveis, diâmetro de colmos e altura de colmos aos 215 DAA $_{\mathrm{HU}}$ Jaboticabal-SP. 2008/2009

\begin{tabular}{|l|c|c|c|c|c|c|c|}
\hline \multirow{2}{*}{ Fonte de variação } & \multicolumn{4}{|c|}{ Fitointoxicação - DAA $\mathrm{HU}_{\mathrm{HU}}$} & Número de & $\begin{array}{c}\text { Diâmetro de } \\
\text { colmos }\end{array}$ & $\begin{array}{c}\text { Altura de } \\
\text { colmos }\end{array}$ \\
\cline { 2 - 8 } & 7 & 15 & 30 & 45 & 0,00 & 2,22 \\
\hline Tratamentos de seca & 0,41 & 2,64 & 0,68 & 0,00 & 1,03 & 0,77 & 1,08 \\
\hline Tratamentos de úmida & $141,53^{* *}$ & $133,62^{* *}$ & $48,80^{* *}$ & 0,00 & 2,04 & 1,76 \\
\hline Trat. seca x Trat. úmida & 0,79 & 1,29 & 0,77 & 0,00 & 1,07 & 1,23 & 1,50 \\
\hline Bloco & 0,78 & 3,31 & 1,45 & 0,00 & 1,67 & 2,16 & 8,58 \\
\hline CV 1 (\%) & 32,96 & 27,52 & 25,01 & 0,00 & 12,93 & 4,93 & 6,39 \\
\hline CV 2 (\%) & 27,91 & 31,11 & 28,24 & 0,00 & 14,00 & 4,60 & 6,44 \\
\hline
\end{tabular}

** Significativo a $1 \%$ de probabilidade pelo teste $\mathrm{F}$ da análise de variância. 
Tabela 11 - Fitointoxicação aos 7, 15 e 30 dias após a aplicação (DAA) de herbicidas na época úmida. Jaboticabal-SP. 2008/09

\begin{tabular}{|l|r|r|r|c|}
\hline \multirow{2}{*}{ Manejo na época úmida } & \multicolumn{4}{c|}{ Fitointoxicação (\%) - DAA } \\
\cline { 2 - 5 } & 7 & 15 & 30 & 45 \\
\hline Mesotrione & $0,00 \mathrm{a}^{1 /}$ & $0,00 \mathrm{a}$ & $0,00 \mathrm{a}$ & 0,00 \\
\hline Mesotrione + ametryn & $18,12 \mathrm{~b}$ & $10,62 \mathrm{~b}$ & $4,69 \mathrm{~b}$ & 0,00 \\
\hline Mesotrione + atrazine & $0,31 \mathrm{a}$ & $0,00 \mathrm{a}$ & $0,00 \mathrm{a}$ & 0,00 \\
\hline Mes.+(diuron+hexazinone) & $30,31 \mathrm{c}$ & $20,31 \mathrm{c}$ & $10,94 \mathrm{c}$ & 0,00 \\
\hline Testemunha capinada 2/ & $0,00 \mathrm{a}$ & $0,00 \mathrm{a}$ & $0,00 \mathrm{a}$ & 0,00 \\
\hline DMS & 4,68 & 3,17 & 2,76 & - \\
\hline
\end{tabular}

${ }^{1 /}$ Médias seguidas da mesma letra não diferem significativamente entre si pelo teste de Tukey a $5 \%$ de probabilidade. ${ }^{2 /}$ Testemunha capinada apenas no dia da pulverização dos herbicidas na época úmida.

Tabela 12 - Número de colmos viáveis de cana em 4,0 metros lineares, diâmetro (mm) e altura de colmos ( $\mathrm{cm})$ aos 215 dias após a aplicação de herbicidas na época úmida (328 dias após a colheita). Jaboticabal-SP. 2008/2009

\begin{tabular}{|l|c|c|c|}
\hline \multicolumn{1}{|c|}{ Manejo na época seca } & $\begin{array}{c}\text { № colmos } \\
(4,0 \text { metros })\end{array}$ & $\begin{array}{c}\text { Diâmetro } \\
(\mathrm{mm})\end{array}$ & $\begin{array}{c}\text { Altura } \\
(\mathrm{cm})\end{array}$ \\
\hline Amicarbazone & 50,92 & 24,62 & 193,59 \\
\hline Imazapic & 49,79 & 24,37 & 198,68 \\
\hline Sulfentrazone & 52,92 & 24,26 & 193,59 \\
\hline Testemunha sem herbicida & 52,17 & 24,11 & 201,24 \\
\hline DMS & 5,99 & 1,08 & 11,33 \\
\hline Manejo na época úmida & $\begin{array}{c}\text { № colmos } \\
(4,0 \text { metros })\end{array}$ & $\begin{array}{c}\text { Diâmetro } \\
(\mathrm{mm})\end{array}$ & $\begin{array}{c}\text { Altura } \\
(\mathrm{cm})\end{array}$ \\
\hline Mesotrione & 51,19 & 24,82 & 200,79 \\
\hline Mesotrione + ametryn & 50,62 & 24,09 & 193,04 \\
\hline Mesotrione + atrazine & 52,19 & 24,28 & 200,55 \\
\hline Mes.+(diuron+hexazinone) & 47,00 & 24,23 & 190,48 \\
\hline Testemunha capinada ${ }^{1 /}$ & 54,31 & 24,08 & 196,97 \\
\hline Testemunha s/manejo & 46,89 & 23,75 & 187,86 \\
\hline DMS & 7,49 & 1,16 & 13,18 \\
\hline
\end{tabular}

1/ Testemunha capinada apenas no dia da pulverização dos herbicidas na época úmida.

complementação de manejo na época úmida. No entanto, para os herbicidas amicarbazone e sulfentrazone houve necessidade da aplicação de mesotrione, isolado ou em mistura com ametryn, atrazine ou diuron + hexazinone, para a manutenção do controle de $E$. heterophylla na época úmida (de 105 a 230 dias após a aplicação na época seca). Quando não foi realizada a aplicação de herbicida na época seca, constatou-se melhor controle de E. heterophylla na época úmida com o herbicida mesotrione associado a ametryn, atrazine ou diuron + hexazinone do que quando ele foi aplicado isoladamente. Nenhum dos manejos adotados ou combinações entre eles interferiu no número de colmos viáveis por metro linear, diâmetro e altura de colmos de cana-de-açúcar.

\section{LITERATURA CITADA}

SISTEMA DE AGROTÓXICOS FITOSSANITÁRIOS AGROFIT. Disponível em: <http://www. extranet.agricultura.gov.br/agrofit_cons/ principal_agrofit_cons $>$ Acesso em 07 de agosto de 2009.

ASSOCIACION LATINOAMERICANA DE MALEZAS ALAM. Recomendaciones sobre unificacion de los sistemas de evaluacion em ensayos de control de malezas. ALAM, v. 1, p. 35-38, 1974.

AZANIA, C. A. M. et al. Manejo químico de Convolvulaceae e Euphorbiaceae em cana-de-açúcar em período de estiagem. Planta Daninha, v. 27, n. 4, p. 841-848, 2009.

CORREIA, N. M.; DURIGAN, J. C. Emergência de plantas daninhas em solo coberto com palha de cana-de-açúcar. Planta Daninha, v. 22, n. 1, p. 11-17, 2004

CORREIA, N. M. et al. Envelhecimento de resíduos vegetais sobre o solo e os reflexos na eficácia de herbicidas aplicados em pré-emergência. Bragantia, v. 66, p. 101-110, 2007.

KISSMANN, K. G.; GROTH, D. Plantas infestantes e nocivas. 2.ed. São Paulo: BASF, 1999. 978 p. (Tomo II)

MARTINS, D. et al. Emergência em campo de dicotiledôneas infestantes em solo coberto com palha de cana-de-açúcar. Planta Daninha, v. 17, n. 1, p. 151-161, 1999.

MONQUERO, P. A. et al. Eficácia de herbicidas em diferentes quantidades de palha de cana-de-açúcar no controle de Euphorbia heterophylla. Planta Daninha, v. 25, n. 3, p. 613-619, 2007.

MONQUERO, P. A. et al. Eficácia de herbicidas aplicados em diferentes épocas e espécies daninhas em área de cana-deaçúcar colhida mecanicamente. Planta Daninha, v. 27, n. 2, p. 309-317, 2009. 
PROCÓPIO, S. O.; SILVA, A. A.; VARGAS, L. Manejo e controle de plantas daninhas em cana-de-açúcar. In: VARGAS, L.; ROMAN, E. S. Manual de manejo e controle de plantas daninhas. 2.ed. Passo Fundo: EMBRAPA Trigo, 2008. 780 p.

RODRIGUES, B. N. Influência da cobertura morta no comportamento dos herbicidas imazaquin e clomazone Planta Daninha, v. 11, n. 1/2, p. 21-28, 1993.

RODRIGUES, B. N.; ALMEIDA, F. L. S. Guia de herbicidas. 5.ed. Londrina: Edição dos autores, 2005. 592 p.

SALVADOR, F. L. et al. Efeito da luz e da quebra de dormência na germinação de sementes de espécies de plantas daninhas. Planta Daninha, v. 25, n. 2, p. 303-308, 2007.

SOCIEDADE BRASILEIRA DA CIÊNCIA DAS PLANTAS DANINHAS - SBCPD. Procedimentos para instalação, avaliação e análise de experimentos com herbicidas. Londrina: 1995. 42 p.
SUDA, C. N. K.; PEREIRA, M. F. D. A. Sensibilidade à luz de sementes de Euphorbia heterophylla L. durante a germinação. R. Bras. Fisiol. Veg., v. 9, n. 1, p. 55-64, 1997.

VELINI, E. D; NEGRISOLI, E. Controle de plantas daninhas em cana crua. In: CONGRESSO BRASILEIRO DA CIÊNCIA DAS PLANTAS DANINHAS, 22., 2000, Foz do Iguaçu. Anais... Foz do Iguaçu: Sociedade Brasileira da Ciência das Plantas Daninhas, 2000. p. 148-164.

VIDAL, R. Ação dos herbicidas. Porto Alegre: Edição do Autor, 2002. 89 p.

TOLEDO, R. E. B. et al. Eficácia do herbicida amicarbazone aplicado sobre a palha ou no solo no controle de plantas daninhas na cultura da cana-de-açúcar. Planta Daninha, v. 27 , n. 2 , p. $319-326,2009$ 